\title{
Studies in Silicone-Polyether Ketone Blend Based High Performance Coating
}

\author{
P.A. Mahanwar" and R.H. Dongre \\ Department of Polymer and Surface Engineering, Institute of Chemical Technology, Mumbai, India \\ * Corresponding author email: pa.mahanwar@ictmumbai.edu.in
}

Received: 29 August 2016 / Revised: 23 September 2016 / Accepted: 15 October 2016 / Published: 16 October 2016

\begin{abstract}
Silicone polymer although have some exceptional superior properties have limitations when it is exposed to harsh chemicals. Poly Ether Ketone (PEK), a high-performance polymer is well known for its resistance towards acid, alkali and many solvents. PEK exhibits good environmental protection with better thermal stability. In the present study, the coatings were prepared using varying ratios of silicone and Poly Ether Ketone (PEK) to study the effect of concentration of PEK on mechanical, chemical, thermal and performance properties. The clear coatings of Silicone/PEK cured films were characterized for TGA, FTIR and evaluated for thermal resistance, corrosion resistance, resistance to $10 \%$ acid, alkali, sodium chloride, detergent solution and humidity resistance. The coating films were found to be stable up to $450{ }^{\circ} \mathrm{C}$ as indicated by TGA analysis. It is seen that the performance of silicone / PEK coating films increases with increasing concentration of PEK.
\end{abstract}

Keywords: Clear coat, Cold blended Coating, PEK, Silicone

\section{Introduction}

The term Silicone $\left(\mathrm{R}_{2} \mathrm{SiO}\right)$ was invented by Fredrick Kipping [1]. From 1940s, the Silicone polymers have been tried and blended with various types of organic polymers [2]. The typical example is development of alkoxy-silanol functional resins as weather resistant coatings developed in 1950 [3]. The properties such as gloss retention, chalking resistance or weather resistance of organic coatings can be significantly increased with small addition of silicone or through silicone modification [4]. The backbone structure of silicone resin contains $\mathrm{Si}-\mathrm{O}$ bonds as shown in figure 1 , which have very high stability due to very high bond breaking strength of about $445 \mathrm{KJ} / \mathrm{mol}$.<smiles>[R][Si]([R])(C)O[Si]([R])([R])OC</smiles>

Figure1: Silicone resin, where $R \& R$ ' in silicone resin mostly represents methyl or/and phenyl

group.
As compared to simple alkyds, silicone modified alkyd resins can be successfully used for higher degree of baking/heat resistance [5]. Aluminium pigmented silicon coating can be used as heat resistant coating where coated surfaces require exposure of more than $300{ }^{\circ} \mathrm{C}$ temperature [6]. The silicone-polyester resin composition system in various composition ratios can also be formulated to work up to $400{ }^{\circ} \mathrm{C}$ and as corrosion resistant coating. The system was tested for 30 days immersion in $3 \% \mathrm{NaCl}$ solution [7-8]. The more cost effective corrosion resistant coating based on silicone acrylic polymer with up to $30 \%$ Silicone loading was developed \& tested at $250{ }^{\circ} \mathrm{C}$ [9]. Similarly, mechanical, chemical and temperature resistance of epoxy resin can be improved when epoxy is cold blended with siliconized acrylate [10]. Siliconeepoxy coatings containing siloxane modified poly acrylate can be prepared to impart hydrophobicity and anticorrosion property in coatings [11]. Poly siloxane modified epoxy resin can be effectively used for good thermal stability, 
Studies in Silicone-Polyether Ketone Blend Based High Performance Coating

flame resistance and epoxy-silicone copolymer developed from methyl phenyl silicone intermediate and Bisphenol Epoxy A have also exhibited excellent thermal stability [12-13]. Despite of its vast application scope, the limitation exists is that $\mathrm{Si}-\mathrm{O}$ bond has around $50 \%$ ionic character and therefore it is prone to undergo hydrolysis very easily in the presence of acid or base [14]. This limitation could be overcome by addition of thermoplastic materials into this thermoset silicone matrix. Thermoplastics with presence of aromatic groups would be desirable. Some of examples are polyether ether ketone (PEEK), polyether sulphone (PES), poly phenylene sulphide and polyether imide (PEI) [15]. Among the available thermoplastic aromatic materials, polyether ketone (PEK) can be prepared by nucleophilic reaction of dihaloaromatic ketones with aromatic bisphenols using various solvents [16]. This poly ether ketone is well known for its resistance to aqueous acids, alkalis and organic solvents [17]. Also it provides excellent mechanical resistance, superior environmental protection and high thermal stability and was reported for devising high performance composites [18]. In addition, the presence of ethylene oxide in siliconepolyether copolymer results in easy water miscibility [19]. Figure 2 represents the basic backbone structure of Poly Ether Ketone (PEK).

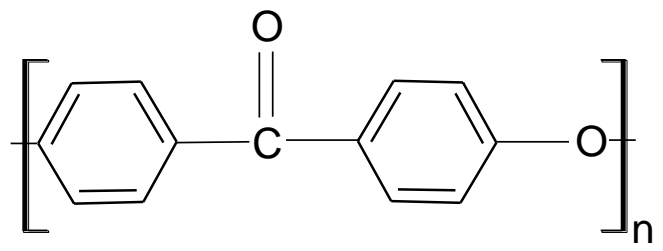

Figure 2: Structures of PEK

In the current work, we have blended silicone resin with thermoplastic PEK to increase the overall chemical and corrosion resistance of the coating while maintaining the other performance properties of the coating system compared to the considered industry standard.

\section{Experimental Work}

\subsection{Materials}

PEK powder from PEK dispersion (G Coat 500 from Gharada Chemicals) was filtered and dried in oven at $150{ }^{\circ} \mathrm{C}$ for 1 hour. Liquid silicon resin
(NVM 50\%) was procured under tradename 808Dow Corning from Dow Chemicals, India and used as it is. Surface active agent K-1540 was procured from K-tech additives, India. Adhesion promoter, flow and levelling agent was obtained from BYK additives under the tradename GLYMO and BYK-420 respectively. HCL, $\mathrm{NaCl}$, $\mathrm{NaOH}$ were procured from SDFCL, India and were used as it is.

\subsection{Methods}

\subsubsection{Coating Formulation}

Varying proportion of silicone-PEK were prepared in the ratios of 9:1, 8:2, 7:3 and $6: 4$ on weight basis and were named as SP91, SP82, SP73 and SP64 respectively for ease of understanding. Their respective compositions were shown in the table 1 . The preparation was carried out by addition of K-1540, GLYMO and BYK-420 into the liquid silicone resin and was stirred to attain a homogeneous solution. Then slow addition of PEK powder into the solution was carried out over the period of $20 \mathrm{~min}$ and stirring was carried out for further $20 \mathrm{~min}$ to attain uniform dispersion. The coating with no PEK material is considered to be the industrial standard through this study.

Table 1: Formulation of silicone-PEK compositions in varying proportion

\begin{tabular}{|c|c|c|c|c|c|}
\hline $\begin{array}{c}\text { Sr. } \\
\text { No }\end{array}$ & Materials & SP 91 & SP 82 & SP 73 & SP 63 \\
\hline $\mathbf{1}$ & $\begin{array}{c}\text { Silicone } \\
\text { Resin }\end{array}$ & 83.7 & 76.26 & 67.89 & 59.52 \\
\hline $\mathbf{2}$ & $\begin{array}{c}\text { PEK } \\
\text { powder }\end{array}$ & 9.3 & 16.74 & 25.11 & 33.48 \\
\hline $\mathbf{3}$ & K 1540 & 5 & 5 & 5 & 5 \\
\hline $\mathbf{4}$ & GLYMO & 1 & 1 & 1 & 1 \\
\hline $\mathbf{5}$ & BYK 420 & 1 & 1 & 1 & 1 \\
\hline \multicolumn{2}{|c|}{ Total } & $100 \%$ & $100 \%$ & $100 \%$ & $100 \%$ \\
\hline
\end{tabular}

\subsubsection{Film application}

Metal panels of dimension $100 \mathrm{~mm}$ x $150 \mathrm{~mm}$ x $0.8 \mathrm{~mm}$ were used for the study. These metal panels are degreased with toluene and dried followed by sanding with emery grade 400 and 800 and wet wiped to ensure cleaned surface. The prepared formulations were applied on using a $150 \mu$ film applicator and cured at $380^{\circ} \mathrm{C}$ for 20 minutes. 
Mahanwar et al., J. Mod. Mater.; Vol. 2, Issue 1, pp: 19-24, 2016

\section{Characterization}

FTIR analysis of the cured films were carried out using Alpha model FTIR from Bruker, USA. Thermo-gravimetric analysis (TGA) was carried out using Pyris 1 from Perkin Elmer India Pvt Ltd. The heating rate of $10{ }^{\circ} \mathrm{C} /$ minute and nitrogen purging rate of $20 \mathrm{ml} / \mathrm{min}$ was maintained during evaluation of all samples under test. The dry film thickness was measured using Model S instrument from Elcometer (ASTM D1005-95). Gloss was evaluated using Gloss-Ometer of Gardner make (ASTM D 523-14). The hardness of the films (ASTM D3363) were evaluated using Staedtler make hardness pencils. Motorized scratch hardness tester was used for evaluating scratch resistance (ASTM D-7027-13). The adhesion was analyzed using cross-cut peel off adhesion method with $3 \mathrm{M}$ adhesion tape. Impact test was carried upto $100 \mathrm{~cm}$ drop down impact tester with dead weight of $1.8 \mathrm{~kg}$ (ASTM 2794-93). The humidity resistance of the films was carried up to $500 \mathrm{~h}$ and were analyzed using ASTM 2247-02. The salt spray tests to evaluate corrosion resistance was carried out as per ASTM B117 using COFOMEGRA make instrument for 500h. Chemical resistance of the coated metal panels were measured by sealing the edges with wax and half immersion of panels in 10 percent aqueous solutions of $\mathrm{HCl}, \mathrm{NaOH}, \mathrm{NaCl}$ and Detergent solution separately at room temperature. The panels were removed for examination after every 24 hours from the start of the test till 500 hours duration. After 500 hours they were tested for loss of adhesion, blistering, popping or any other deterioration of the film. Furthermore, quenching test of the films were carried out by heating the panels to $250{ }^{\circ} \mathrm{C}$ for 30 min and were immersed in water at room temperature to check the adhesion of the films. Heat stability test was carried out by heating panels to $250{ }^{\circ} \mathrm{C}$ for 500 hours and checked for any visual defects.

\section{Results and Discussion}

\subsection{FTIR Analysis of Prepared Silicone: PEK Combinations}

FTIR spectra of Silicone, PEK and Silicone-PEK films were recorded as shown in figure 3.

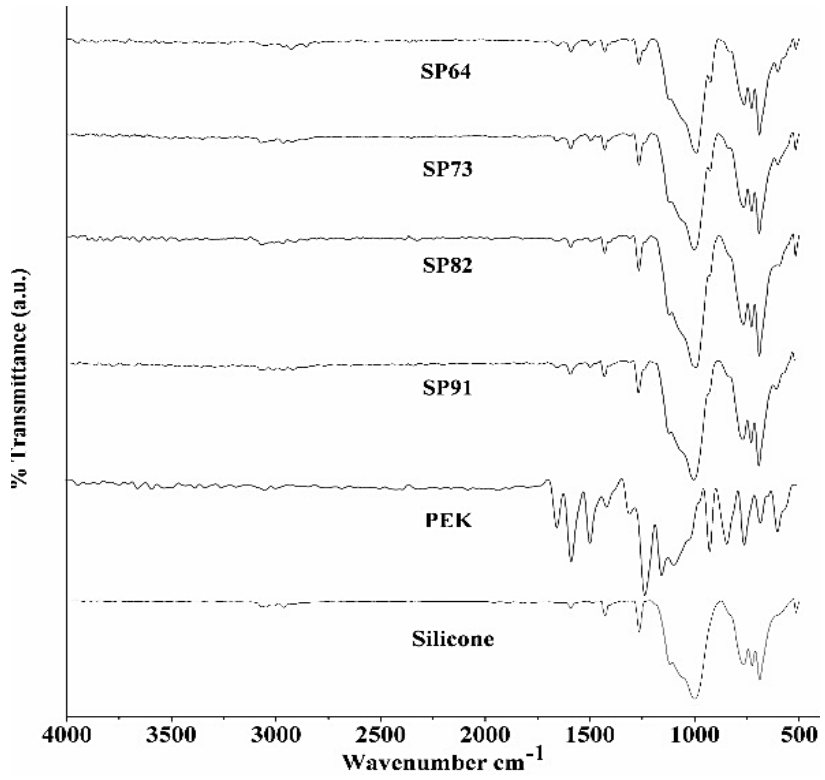

Figure 3: Overlay FTIR plot of Silicone/PEK Blend

The bands at $1250 \mathrm{~cm}^{-1}$ and $1650 \mathrm{~cm}^{-1}$ indicate the presence of ether (C-O) linkages and carbonyl $(\mathrm{C}=\mathrm{O})$ linkages from polyether ketone. The strong intense peak at $1000 \mathrm{~cm}^{-1}$ indicate the stretching frequency of $\mathrm{Si}-\mathrm{O}$ bonds from silicone resin. Also the absence of peaks at $3200 \mathrm{~cm}^{-1}$ and $3400 \mathrm{~cm}^{-1}$ indicate the absence of hydroxyl groups in the sample. Apart from this, the peaks at the bands in the region 770 to $710 \mathrm{~cm}^{-1}$ indicate the strong presence of aromatic $\mathrm{C}-\mathrm{H}$ groups from phenyl structures. The medium/weak peaks in the range between $1400 \mathrm{~cm}^{-1}-1500 \mathrm{~cm}^{-1}$ indicate the $\mathrm{C}=\mathrm{C}$ stretching frequency of the aromatic rings. From IR spectra it can be inferred that there is no chemical reaction between both the polymeric

phases as the characteristic peaks of both the phases remain unchanged indicating that there is only formation of inter penetrating network.

\subsection{TGA Analysis}

The cured film of Silicone, PEK, and cured films of Silicone: PEK composition for SP91, SP82, SP73 and SP64 were tested for their thermal stability by thermo gravimetric analysis (TGA) and the TGA curves are shown in figure 4. The onset and offset points from the curves are tabulated in table 2. From Table 2, it can be inferred that with addition of $20 \%$ PEK with silicone the onset of degradation is delayed and starts at $489{ }^{\circ} \mathrm{C}$. The inter penetrating structure 
Studies in Silicone-Polyether Ketone Blend Based High Performance Coating

of PEK and silicone containing 20\% PEK allows the blend to attain the highest peak temperature of $623.62^{\circ} \mathrm{C}$.

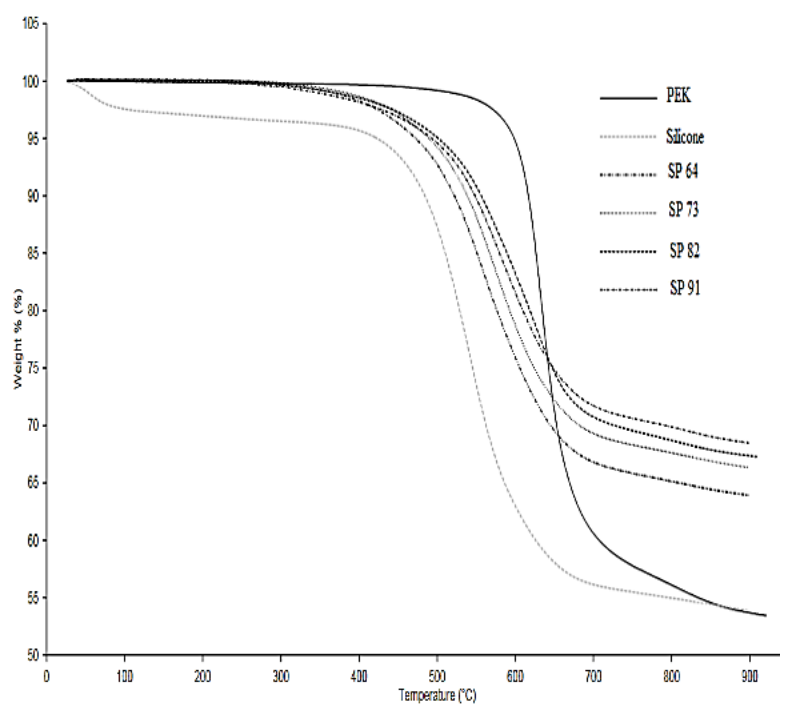

Figure 4: TGA Plot of Silicone / PEK Blend thermal stability. The result obtained could be attributed to the fact that backbone structure of Silicone polymer contains inorganic Si-O linkages and requires higher energy to break this bond.

Table 2: Onset, Offset temperature, Total weight loss and Residue weight (\%) of Silicone, PEK, Silicone: PEK compositions

\begin{tabular}{|c|c|c|c|c|c|c|}
\hline $\begin{array}{l}\text { S. } \\
\text { N. }\end{array}$ & $\begin{array}{c}\text { Sam } \\
\text { ple } \\
\text { Nam } \\
\text { e }\end{array}$ & $\begin{array}{c}\text { Total } \\
\text { Weigh } \\
\text { t loss } \\
(\%)\end{array}$ & $\begin{array}{c}\text { Onset } \\
\text { temper } \\
\text { ature } \\
\left({ }^{\circ} \mathrm{C}\right)\end{array}$ & $\begin{array}{c}\text { Offset } \\
\text { temper } \\
\text { ature } \\
\left({ }^{0} \mathrm{C}\right)\end{array}$ & $\begin{array}{c}\text { Max. } \\
\text { peak } \\
\text { tempe } \\
\text { rature } \\
\left({ }^{0} \mathrm{C}\right)\end{array}$ & $\begin{array}{c}\text { Residue } \\
\text { weight } \\
(\%)\end{array}$ \\
\hline 1 & $\begin{array}{l}\text { PEK } \\
\end{array}$ & 46.511 & $\begin{array}{l}591.79 \\
\end{array}$ & 683.12 & 634.36 & 53.663 \\
\hline 2 & $\begin{array}{l}\text { Silic } \\
\text { one }\end{array}$ & 46.011 & 448.71 & 621.32 & 540.81 & 53.901 \\
\hline 3 & SP91 & 31.511 & $\begin{array}{l}474.49 \\
\end{array}$ & $\begin{array}{l}708.79 \\
\end{array}$ & 584.65 & 68.481 \\
\hline 4 & SP82 & 32.736 & 489.00 & 694.70 & 623.62 & 67.354 \\
\hline 5 & SP73 & 33.602 & 476.88 & 687.56 & 574.39 & 66.359 \\
\hline 6 & SP64 & 36.071 & 458.63 & 700.10 & 558.32 & 63.926 \\
\hline
\end{tabular}

This analysis indicates that all films have good thermal stability with SP 82 having overall best

Table 3: Mechanical resistance properties of Silicon, PEK and composite samples

(Pass indicates no abnormality in the coating film after testing was performed as per the standard procedure)

\begin{tabular}{|l|l|l|l|l|l|l|l|}
\hline S No & Parameters & Silicone & PEK & SP91 & SP82 & SP73 & SP64 \\
\hline $\mathbf{1}$ & DFT & $67-70 \mu$ & $70-75 \mu$ & $70-75 \mu$ & $70-75 \mu$ & $67-75 \mu$ & $70-72 \mu$ \\
\hline $\mathbf{2}$ & Gloss at $\mathbf{6 0}^{\mathbf{0}}$ & 58 & 58 & 24 & 25 & 34 & 45 \\
\hline $\mathbf{3}$ & Pencil Hardness & $6 \mathrm{H}$ Pass & 6H Pass & 6H Pass & $6 \mathrm{H}$ Pass & $6 \mathrm{H}$ Pass & 6H Pass \\
\hline $\mathbf{4}$ & Scratch Hardness & $1.2 \mathrm{kgPass}$ & $3.5 \mathrm{kgPass}$ & $1.5 \mathrm{~kg}$ pass & $1.7 \mathrm{~kg}$ Pass & $3.0 \mathrm{~kg}$ Pass & $3.5 \mathrm{~kg}$ Pass \\
\hline $\mathbf{5}$ & Impact Resistance & Pass & Pass & Pass & Pass & Pass & Pass \\
\hline $\mathbf{6}$ & Quenching test & Pass & Pass & Pass & Pass & Pass & Pass \\
\hline $\mathbf{7}$ & $\begin{array}{l}\text { Humidity } \\
\text { resistance }\end{array}$ & Pass & Pass & Pass & Pass & Pass & Pass \\
\hline $\mathbf{8}$ & Salt Spray resistance & 144 Hours & $>500$ Hours & $\begin{array}{l}250 \\
\text { Pass Hours }\end{array}$ & 275 Hours & 315 Hours & 400 Hours \\
\hline $\mathbf{9}$ & Heat Stability & Pass & Pass & Pass & Pass & Pass & Pass \\
\hline
\end{tabular}

\subsection{Physicochemical Testing of Silicone-PEK Composition}

The coating performance of silicone, PEK and Silicone-PEK films were evaluated and results were tabulated in table 3. As the PEK quantity was found to increase the mechanical performance of the films were found to increase. This might be due to the excellent compatibility of material with each other. In addition, even the corrosion performance of the film increased with higher PEK content due to the presence of stable 
Mahanwar et al., J. Mod. Mater.; Vol. 2, Issue 1, pp: 19-24, 2016

aromatic and ether linkages. The corrosion test results were displayed in figure 5 .

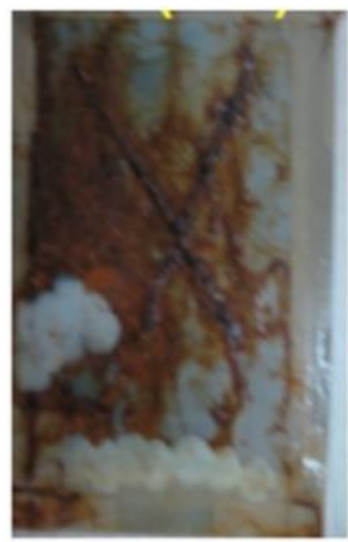

SP 91

(a)

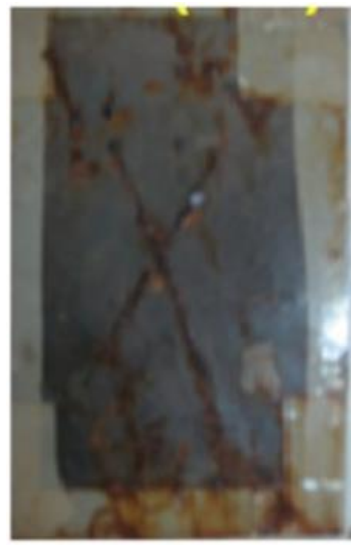

SP 73

(c)

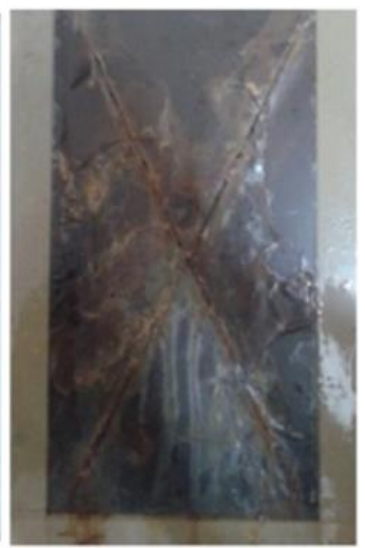

SP 82

(b)

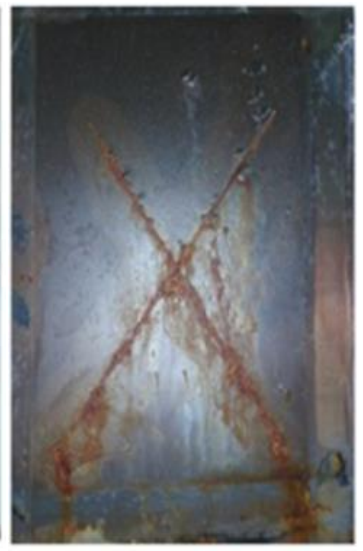

SP 64

(d)
Figure 5: Salt spray resistance test for (a) SP 91, (b) SP 82 (c) SP 73 and (d) SP 64 Coating panels for 500 hours

Even after 500 hours of panel exposure to $250{ }^{\circ} \mathrm{C}$ in heat stability test, no abnormality was found in any of the mechanical performance properties of the films before and after testing. The results of chemical resistance testing of the coated films were given by the figure 6 .

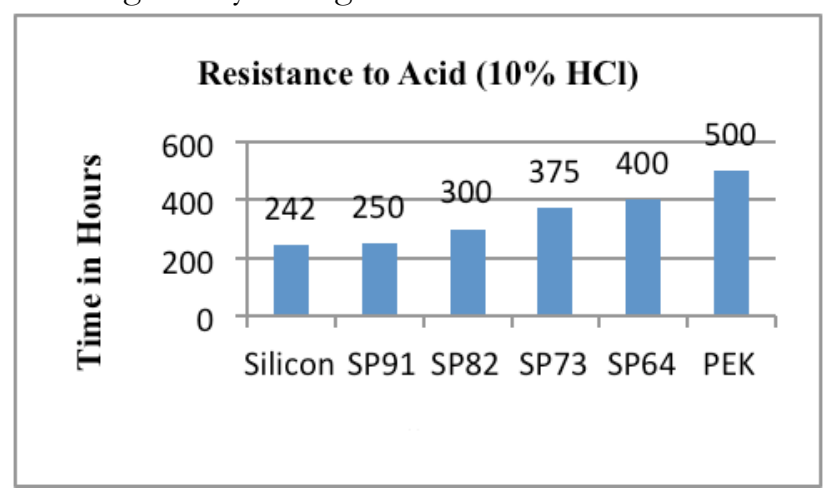

(a)
Resistance to Alkali (10\% $\mathrm{NaOH})$

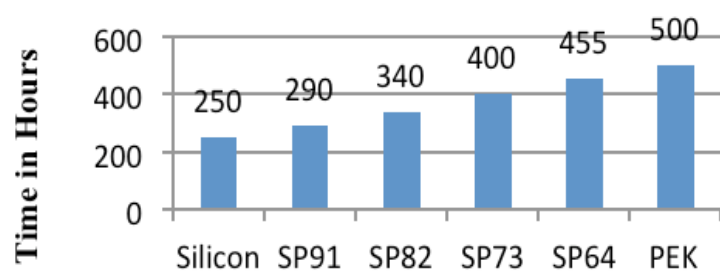

(b)

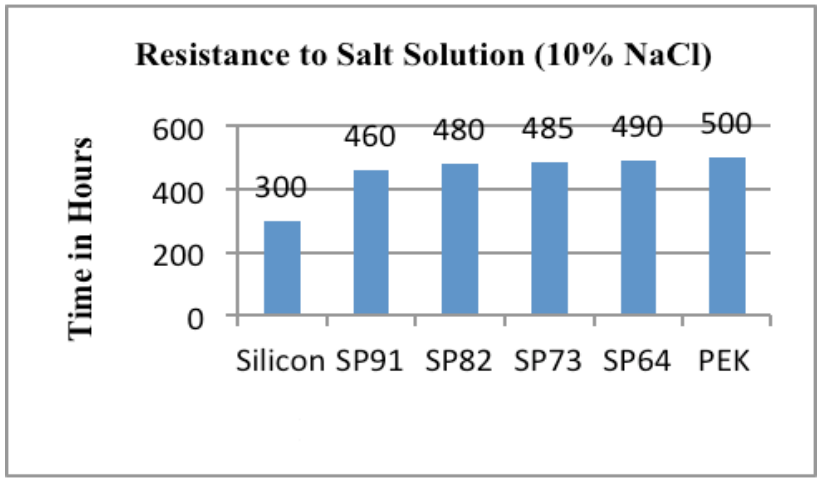

(c)

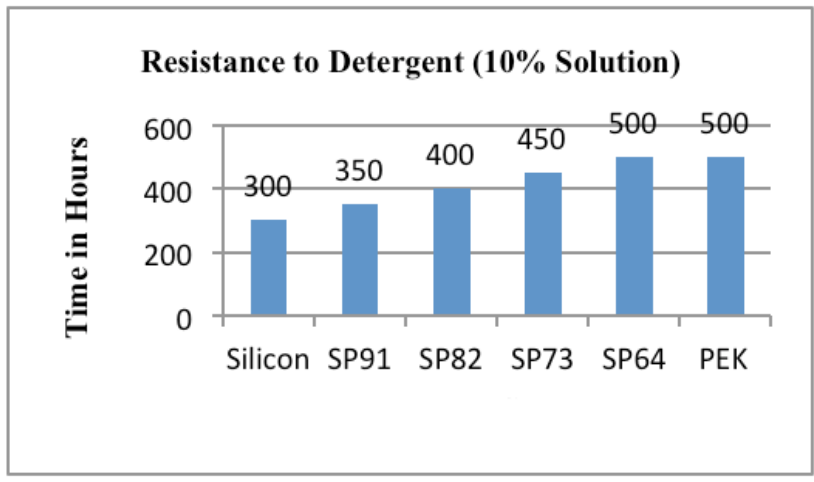

(d)

Figure 6: Chemical Resistance for Silicone: PEK blended coating: (a) Resistance to acid, (b) Resistance to alkali, (c) Resistance to $\mathrm{NaCl}$

Solution, (d) Resistance to detergent solution

It is evident from the figure 6 that with increase in PEK content increases the chemical resistance of the films irrespective of acid, alkali, salt and detergent solution. This is due to the inherent chemical resistance characteristics of PEK. Overall the composition of SP64 was found to be superior in mechanical, corrosion and chemical resistance of the films comparatively.

\section{Conclusions}

PEK was added into silicone matrix in varying proportions from $10 \%$ to $40 \%$ to enhance the chemical performance of the silicone coatings 
without compromise in mechanical and other performance properties. FTIR analysis indicated the characteristic carbonyl, ether and Si-O linkages present in the films indicating no occurrence of any chemical reaction during curing. TGA studies indicated the decrease in thermal stability with increase in PEK content although the extent of decrement is slight which is well in agreement that increasing organic content reduces the thermal stability. The mechanical performance characteristics of the films were excellent in comparison to the standard which indicates the good compatibility between PEK and silicone resin. Furthermore, chemical resistance of the films significantly increased with increasing PEK content. In addition, the films were also found to be corrosion and humidity resistance with excellent thermal stability.

\section{Acknowledgements}

Authors of this paper extend their cordial thanks to Dr. H. M Natu, (Gharada Chemicals, India), Dr. Subhash Srivastava, (K-TECH additives, India) \& Dr. Mandar Mule (BYK India) for providing raw materials for this work.

\section{How to Cite this Article:}

R. Dongre and P. Mahanwar, "Studies in Silicone-Polyether Ketone Blend Based High Performance Coating", J. Mod. Mater., vol. 2, no. 1, pp. 19-24, Oct. 2016. doi:10.21467/jmm.2.1.19-24

\section{References}

[1] A. Colas, \&L. Aguadisch, "Silicones In Industrial applications", Chimie Nouvelle 15 (58), 779, 1997.

[2] E.G.,Rachow "Silicon and Silicones", Springer-Verlag: Berlin, Heidelberg, New York, 1987.

[3] B.Harman,"Encyclo. Polymeric Science Engg.", 15,201, 1989.

[4] N.R. Mowrer, "Polysiloxane Coating Innovations AmeronInt Brea C A. Technology”, Silicones In Coatings, Presentationon.

[5] H L. Brown, "Silicones in protective coatings in treaties on coatings" Marcel Dekker Inc., Film Forming compositions, Vol.I, part III;New York, 1972.

[6] Shinkareva, E. V., et al. "Effect of silicone resins and laminar filler on oxidation of aluminum particles with atmospheric oxygen. Heat-resistant coatings based on these materials." Russian Journal of Applied Chemistry, vol. 88, no. 5, pp. 846-51, 2015.

[7] K. Ramesh, S. Ramesh, B. Vengadaesvaran, A.K. Arof., "Silicone-Polyester blended coatings for Corrosion protection", International Journal of Fundamental Physical Sciences, Volume 1, No.4, pp.83-86, 2011.

[8] Ramesh, K., et al. "Structural and corrosion protection analyses of coatings containing silicone-polyester resins." Pigment \& Resin Technology, vol. 37, no. 1, pp. 37-41, 2008.

[9] Chew, K. W., et al. "Chemical and heat resistance of silicone-acrylic-based binder and paint system on mild steel panels." Pigment \& Resin Technology, vol. 36, no. Issue: 5, pp. 286-92, 2007.

[10] Firdous Habib, Madhu Bajpai, "UV Curable heat resistance Epoxy Acrylate Coatings"Journal of Chemistry \& Chemical Technology, Vol.4, No.3, pp.205-216, 2010.

[11] Yuan, X., et al. "Effect of Siloxane modified polyacrylate on water uptake and anticorrosion mechanism of siliconeepoxy coatings" Journal of Coatings Technology and Research, vol. 13, no. 1, pp. 123-32, 2016.

[12] Liu, Qiang, et al. "The Investigation of methyl phenyl silicone resin/epoxy resin using Epoxy-Polysiloxane as compatibilizer." Journal of Thermal Analysis and Calorimetry, vol. 118, no. 1, pp. 247-54, 2014.

[13] Zengguang Heng, Zhong Zeng, Yang Chen, Huawei Zou, Mei Liang, "Silicone modified epoxy resin with good toughness, damping properties and high thermal residual weight"- Journal of Polymer Research, - 22:203, pp. 1-7, 2015.

[14] W. Noll, "Chemistry \& Technology of Silicones", Academic press, New York, 1968.

[15] https://en.wikipedia.org/wiki/High_performance plastics (accessed on 07.08.2016)

[16] V.L. Rao and P. ShivaDasan, "Synthesis and properties of poly ether ketones", European Polymer Journal, Vol. 30, No, 12, pp. 1381-1388, 1994.

[17] David Parker,Jan Bussink, T. Hendrik "Polymers, HighTemperature".Ullmann's Encyclopedia of Industrial Chemistry, pub 3, pp.21-449, 2014.

[18] Vasconcelos, Gibran da Cunha, "Evaluation of Decomposition Kinetics of Poly (Ether-Ether-Ketone) by thermogravimetric analysis"Materials Research, vol.17, n.1, pp.227-235, 2014.

[19] T. Easton and M. Stones, "Surface Coating International", OCCCA, Wembley, London, 82 (11), 549, 1998.

Publish your research article in AIJR journals-

$\checkmark$ Online Submission and Tracking

$\checkmark$ Peer-Reviewed

$\checkmark$ Rapid decision

$\checkmark$ Immediate Publication after acceptance

$\checkmark$ Articles freely available online

$\checkmark \quad$ Retain full copyright of your article.

Submit your article at journals.aijr.in

Publish your books with AIJR publisher-

$\checkmark$ Publish with ISBN and DOI

$\checkmark$ Publish Thesis/Dissertation as Monograph.

$\checkmark$ Publish Book Monograph.

$\checkmark$ Publish Edited Volume/ Book.

$\checkmark$ Publish Conference Proceedings

$\checkmark$ Retain full copyright of your books.

Submit your manuscript at books. aijr.org 